\title{
DIAGONALISASI DUA MATRIKS HERMITE SECARA SIMULTAN
}

Try Azisah Nurman ${ }^{\mathrm{i}}$, Nur Aeni ${ }^{\mathrm{ii}}$, Sudarti Dahsan ${ }^{\mathrm{iii}}$

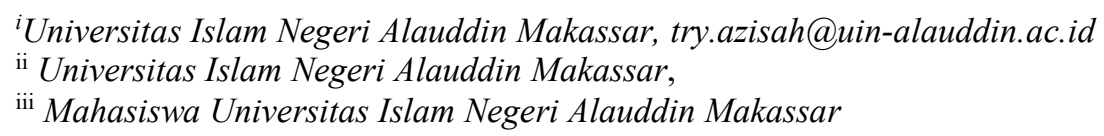

\begin{abstract}
ABSTRAK, Matriks Kompleks merupakan matriks yang entri-entrinya bilangan kompleks. Matriks kompleks terdiri dari matriks hermite, matriks satuan (uniter) dan matriks normal. Tujuan dalam penelitian ini adalah untuk mendiagonalisasi dari dua matriks hermite secara simultan. Suatu matriks hermite A dan B terdiagonalisasi secara simultan jika $\mathrm{AB}=\mathrm{BA}$. Langkah pertama mendiagonalisasi matriks hermite $A$ adalah menentukan basis untuk masing-masing ruang eigen. Selanjutnya, menormalisasikan masing-masing basis bagi masingmasing ruang eigen, kemudian membentuk matriks $\mathrm{P}$ yang kolom-kolomnya adalah vektor-vektor basis. Untuk mendiagonalisasi matriks A dan B secara simultan menggunakan persamaan $\mathrm{D}_{1}=\mathrm{P}^{*} \mathrm{AP}$ dan $\mathrm{D}_{2}=\mathrm{P}^{*} \mathrm{BP}$. Untuk matriks $\mathrm{A}$ dan $\mathrm{B}$ ordo $2 \times 2$ diperoleh $\mathrm{D}_{1}=\left[\begin{array}{cc}2+\sqrt{2} & 0 \\ 0 & 2-\sqrt{2}\end{array}\right]$ dan $\mathrm{D}_{2}=\left[\begin{array}{cc}1+\sqrt{2} & 0 \\ 0 & 1-\sqrt{2}\end{array}\right]$. Untuk matriks $A$ dan $B$ ordo $3 \times 3$ diperoleh $\mathrm{D}_{1}=$ $\left[\begin{array}{ccc}1 & 0 & 0 \\ 0 & 1+\sqrt{5} & 0 \\ 0 & 0 & 1-\sqrt{5}\end{array}\right]$ dan $\mathrm{D}_{2}=\left[\begin{array}{ccc}2 & 0 & 0 \\ 0 & 2+\sqrt{5} & 0 \\ 0 & 0 & 2-\sqrt{5}\end{array}\right]$
\end{abstract}

Kata Kunci: Diagonalisasi, Matriks, Matriks Hermite, Simultan

\section{PENDAHULUAN}

Diagonalisasi matriks memainkan peran yang sangat penting dalam aljabar dan juga merupakan penerapan dari nilai eigen dan vektor eigen yang lebih memusatkan pada persoalan penentuan sebuah basis untuk ruang vektor yang terdiri vektor-vektor eigen sebuah matriks $A_{n \times n}$, yang telah ditentukan. Diagonalisasi secara ortogonal pada matriks simetris dalam ruang vektor riil dimana matriks ortogonal $\left(A^{-1}=A^{t}\right)$. Pada umumnya diagonalisasi matriks dalam ruang vektor riil lebih banyak dilakukan dibanding ruang vektor kompleks. Untuk diagonalisasi dalam ruamg vektor kompleks, peranan utama dipegang oleh dua kelas matriks baru yaitu matriks uniter dan matriks hermite dimana keduanya memiliki elemen-elemen bilangan kompleks.

Bilangan Kompleks adalah bilangan yang berbentuk $a+b i$ dimana $a$ dan $b$ adalah bilangan riil, dan $i$ adalah bilangan imajiner tertentu yang mempunyai sifat $i^{2}=-1$.
Bilangan kompleks dapat ditambah, dikurang, dikali dan dibagi seperti bilangan riil namun bilangan kompleks juga mempunyai sifat-sifat tambahan yang menarik.

Salah satu matriks yang entrinya memuat bilangan kompleks adalah matriks hermite. Matriks Hermite menikmati banyak sifat-sifat matriks real simetri tetapi tidak semuanya dapat didiagonalkan secara uniter, namun matriks real simetri adalah satu-satunya matriks dengan unsur real yang dapat didiagonalkan secara ortogonal.

Diagonalisasi secara ortogonal pada matriks simetris dalam ruang vektor riil dimana matriks ortogonal $\left(A^{-1}=A^{t}\right)$ dan matriks simetris $\left(A=A^{t}\right)$ memainkan peranan yang sangat penting di dalam permasalahan diagonalisasi tersebut.Diagonalisasi matriks dapat dilakukan pada matriks dengan unsur bilangan riil maupun pada matriks dengan unsur bilangan kompleks. Melakukan diagonalisasi pada matriks yang mempunyai unsur bilangan kompleks tidak jauh berbeda dengan diagonalisasi pada matriks dengan bilangan riil, ini berkaitan dengan sifatsifat yang dimiliki oleh bilangan kompleks. Berbeda dengan ruang vektor riil, dalam ruang vektor kompleks matriks mempunyai nilai eigen. Diagonalisasi matriks dengan unsur bilangan kompleks dilakukan pada matriks Hermite

\section{TINJAUANPUSTAKA}

\section{BILANGAN KOMPLEKS}

\section{Definisi 2.1}

Bilangan kompleks adalah sebuah pasangan berurutan bilangan riil yang dinotasikan oleh $(a, b)$ atau $a+b i$, dimana $i^{2}=-1$.

\section{Definisi 2.2}

Dua bilangan kompleks, $a+b i$ dan $c+d i$, didefinisikan sebagai sama (equal) dan dituliskan

$$
a+b i=c+d i
$$

jika $a=c$ dan $b=d$. 
Jika $b=0$ maka bilangan kompleks $a+b i$ tereduksi menjadi $a+0 i$ atau dituliskan sebagai $a$ saja. Dengan demikian, untuk setiap bilangan riil $a$

$$
a=a+0 i
$$

sehingga semua bilangan riil dapat dianggap sebagai bilangan kompleks dengan bagian imajiner yang sama dengan nol. Jika didapatkan $a=0$, maka $a+b i$ tereduksi menjadi $0+b i$ yang biasanya dituliskan sebagai $b i$ saja. Bilangan-bilangan kompleks semacam ini disebut bilangan imajiner murni (pure imaginary number).

Vektor-vektor pada $R^{2}$ dijumlahkan dengan cara menjumlahkan komponen-komponen yang bersesuaian, maka pada bilangan-bilangan kompleks dijumlahkan dengan cara menjumlahkan bagian-bagian riilnya secara bersama-sama dan menjumlahkan bagianbagian imajinernya bersama-sama:

$(a+b i)+(c+d i)=(a+c)(b+d)$

Operasi pengurangan dan perkalian dengan sebuah bilangan riil juga menyerupai operasi vektor yang bersesuaian pada $R^{2}$ :

$(a+b i)-(c+d i)=(a-c)+(b-d) i$

$k(a+b i)=(k a)+(k b) i$

dimana $k$ adalah bilangan riil

\section{MATRIKS HERMITE}

Definisi 2.3

Sebuah matriks bujursangkar $A$ yang entrientrinya bilangan kompleks disebut matriks hermitian jika

\section{Contoh:}

$$
A=A^{*}
$$

Jika Terdapat suatu matriks $A$ yang entrientrinya bilangan kompleks seperti pada matriks berikut ini:

$$
\begin{gathered}
A=\left[\begin{array}{ccc}
3 & 2-i & 4-7 i \\
2+i & 4 & 3-2 i \\
4+7 i & 3+2 i & 2
\end{array}\right] \\
\bar{A}=\left[\begin{array}{ccc}
3 & 2+i & 4+7 i \\
2-i & 4 & 3+2 i \\
4-7 i & 3-2 i & 2
\end{array}\right] \text { sehingga } \\
A^{*}=\bar{A}^{t}=\left[\begin{array}{ccc}
3 & 2-i & 4-7 i \\
2+i & 4 & 3-2 i \\
4+7 i & 3+2 i & 2
\end{array}\right]=A .
\end{gathered}
$$

Jadi $A$ adalah Hermite $\bar{A}$ adalah Konjugat Matriks dari $A$
$A^{*}$ dan $\bar{A}^{t}$ adalah Konjugat Transpose dari Matriks $A$

Untuk mengenali matriks Hermite maka dapat dilihat entri-entri pada diagonal utamanya adalah bilangan-bilangan real dan "bayangan cermin" tiap-tiap entri yang terletak berseberangan dengan diagonal utama adalah konjugat kompleksnya.

\section{PROSES GRAM-SCHMIDT}

Proses Gram-Schmidt merupakan langkahlangkah yang digunakan untuk mengkonversikan suatu basis sebarang menjadi sebuah basis ortogonal. Setelah basis ortogonal diperoleh, selanjutnya dilakukan normalisasi untuk memperoleh sebuah basis ortonormal. Jika $\boldsymbol{U}=\left(\boldsymbol{u}_{\mathbf{1}}, \boldsymbol{u}_{\mathbf{2}}, \ldots, \boldsymbol{u}_{\boldsymbol{n}}\right)$ adalah sebuah basis ortogonal untuk sebuah ruang vektor $\boldsymbol{V}$ maka untuk menormalisasikan tiap-tiap vektor di dalam basis ortogonal adalah

Dimana :

$$
v_{i}=\frac{u_{i}}{\left\|u_{i}\right\|}
$$

$u_{i}=$ basis sebarang untuk $V$.

$v_{i}=$ basis ortonormal untuk $V$

$\left\|u_{i}\right\|=\langle u, u\rangle^{1 / 2}=\sqrt{\left|u_{1}\right|^{2}+\left|u_{2}\right|^{2}+\cdots+\left|u_{n}\right|^{2}}$

\section{DIAGONALISASI MATRIKS}

Definisi 2.4:

Sebuah matriks bujur sangkar $A$ dikatakan dapat didiagonal (diagonalizable) jika ada matriks $P$ yang dapat dibalik (invertible) sehingga $P^{-1} A P$ diagonal, maka $P$ dikatakan mendiagonalisasi matriks $A$.

Suatu matriks bujursangkar $A$ dikatakan dapat dibawa (direduksi) ke bentuk diagonal oleh suatu transformasi similaritas bila terdapat matriks nonsingular $P$ sehingga $P^{-1} A P=I$. Syarat perlu dan cukup bahwa matriks $A$ ordo $n$ dapat dibawa ke bentuk diagonal (similar dengan suatu matriks diagonal) adalah $A$ mempunyai $n$ buah vektor karakteristik yang bebas linear.

Teorema 2.1.

Jika $A$ adalah matriks $n \times n$, maka pernyataanpernyataan berikut ekuivalen satu sama lain.

1. A dapat didiagonalisasi

2. $A$ mempunyai $n$ vektor eigen bebas linear 
DIAGONALISASI SECARA ORTOGONAL Definisi 2.5:

Sebuah matriks bujur sangkar $A$ dikatakan secara ortogonal dapat didiagonalisasikan jika terdapat sebuah matriks ortogonal $P$ sehingga $P^{-1} A P=P^{t} A P$ adalah matriks diagonal, matriks $P$ dikatakan secara ortogonal mendiagonalisasi $A$.

\section{Teorema 2.2:}

Jika $A$ adalah matriks $n \times n$, maka pernyataanpernyataan berikut ekuivalen satu sama lain.

1. A dapat didiagonalisasi secara ortogonal

2. A mempunyai sebuah himpunan ortogonal dari $n$ vektor eigen yang ortonormal

3. A adalah matriks simetrik

\section{DIAGONALISASI SECARA UNITER}

Definisi 2.10:

Sebuah matriks bujur sangkar $A$ dengan elemenelemen kompleks dikatakan secara uniter dapat didiagonalisasi apabila terdapat sebuah matriks uniter $P$ yang sedemikian rupa sehingga $P^{-1} A P=P^{*} A P$ adalah matriks diagonal, maka matriks $P$ dikatakan secara uniter mendiagonalisasi $A$.

Teorema 2.3:

Jika Amatriks bujur sangkar dengan unsur kompleks, maka pernyataan berikut ekuivalen (setara):

a. $A$ dapat didiagonalkan secara uniter.

b. Amempunyai himpunan ortonormal dari $n$ vektor eigen.

c. A normal.

\section{DIAGONALISASI SIMULTAN}

Jika $A$ dan $B$ adalah dua buah matriks Hermite dengan ordo yang sama dan keduanya komutatif, maka matriks tersebut dapat didiagonalkan secara simultan dengan sebuah matriks $P$, yaitu, jika

$$
D_{1}=P^{-1} A P \text { dan } D_{2}=P^{-2} B P
$$

Dengan $D_{1}$ dan $D_{2}$ adalah matriks diagonal, Sehingga $A B=B A$

\section{METODOLOGI}

penulisan ini ialah kajian pustaka yakni yang memanfaatkan sumber kepustakaan yang terdapat di perpustakaan dan internet untuk memperoleh informasi penelitian tanpa melakukan riset lapangan dengan mengumpulkan beberapa literature baik berupa buku maupun jurnal yang berkaitan dengan penelitian ini

\section{Prosedur Analisis}

Langkah-langkah yang diambil dijelaskan sebagai berikut:

1. Menentukan dua matriks yang merupakan matriks Hermite, misalnya Matriks A dan B.

2. Menunjukkan bahwa matriks $A$ dan $B$ bersifat komutatif yaitu $\mathrm{AB}=\mathrm{BA}$

3. Menentukan sebuah basis untuk masingmasing ruang eigen matriks

4. Menormalisasikan masing-masing basis bagi masing-masing ruang eigen

5. Membentuk matriks $P$ yang kolomkolomnya adalah vektor-vektor basis yang dibangun dilangkah 4

6. Mendiagonalisasi matriks A dan B secara simultan.

\section{PEMBAHASAN}

\section{Penentuan Matriks Hermite}

Penentukan dua matriks hermite yang terdiri dari matriks hermite $A$ dan matriks hermite $B$ dengan syarat diagonal utama matriks hermite $A=n$ dan diagonal utama matriks hermite $B=$ $m$, dengan ketentuan tiap baris dan kolom kedua matriks hermite $A$ dan $B$ bernilai sama kecuali diagonal utama.

Dua matriks berordo 2 × 2 yang digunakan dalam tulisan ini adalah

$$
\begin{aligned}
& A=\left[\begin{array}{cc}
2 & 1+i \\
1-i & 2
\end{array}\right] \\
& B=\left[\begin{array}{cc}
1 & 1+i \\
1-i & 1
\end{array}\right]
\end{aligned}
$$

\section{Menunjukkan bahwa kedua matriks bersifat komutatif}

Kedua matriks memenuhi sifat komutatif sebagai berikut:

$$
\begin{aligned}
& A B=\left[\begin{array}{cc}
2 & 1+i \\
1-i & 2
\end{array}\right]\left[\begin{array}{cc}
1 & 1+i \\
1-i & 1
\end{array}\right]=\left[\begin{array}{cc}
4 & 3+3 i \\
3-3 i & 4
\end{array}\right] \\
& B A=\left[\begin{array}{cc}
1 & 1+i \\
1-i & 1
\end{array}\right]\left[\begin{array}{cc}
2 & 1+i \\
1-i & 2
\end{array}\right]=\left[\begin{array}{cc}
4 & 3+3 i \\
3-3 i & 4
\end{array}\right]
\end{aligned}
$$




\section{Penentuan basis ruang eigen matriks}

Setelah diperoleh nilai eigen $\lambda_{1}=2+\sqrt{2}$ dengan ruang eigen $\boldsymbol{u}_{\mathbf{1}}=\left[\begin{array}{c}\frac{-1-i}{\sqrt{2}} \\ -1\end{array}\right]$ dan $\lambda_{2}=2-\sqrt{2}$ dengan ruang eigen $\boldsymbol{u}_{2}=\left[\begin{array}{c}\frac{1+i}{\sqrt{2}} \\ -1\end{array}\right]$.

\section{Penormalisasian basis ruang eigen matriks}

Kedua basis tersebut dinormalkan dengan menggunakan proses Gram-Schmidt diperoleh $\boldsymbol{p}_{1}=\left[\begin{array}{c}\frac{-1-i}{2} \\ \frac{-1}{\sqrt{2}}\end{array}\right]$ dan $\boldsymbol{p}_{2}=\left[\begin{array}{c}\frac{1+i}{2} \\ \frac{-1}{\sqrt{2}}\end{array}\right]$ sehingga terbentuk matriks $\boldsymbol{P}=\left[\begin{array}{cc}\frac{-1-i}{2} & \frac{1+i}{2} \\ \frac{-1}{\sqrt{2}} & \frac{-1}{\sqrt{2}}\end{array}\right]$.

\section{Pendiagonalisasian matriks}

Dengan menggunakan matriks $\boldsymbol{P}$ ini, terlebih dahulu matriks $P$ yang telah dibentuk akan dikonversi menjadi $P^{*}$ dimana $P^{*}$ adalah konjugat transpose dari matriks. Kemudian kita mendiagonalisasi matriks $\boldsymbol{A}$ dan $\boldsymbol{B}$ secara simultan, dengan menggunakan persamaan $D_{1}=P^{*} A P$ dan $D_{2}=P^{*} B P$ dimana diperoleh

$$
\begin{aligned}
& D_{1}=P^{*} A P=\left[\begin{array}{cc}
2+\sqrt{2} & 0 \\
0 & 2-\sqrt{2}
\end{array}\right] \\
& D_{2}=P^{*} B P=\left[\begin{array}{cc}
1+\sqrt{2} & 0 \\
0 & 1-\sqrt{2}
\end{array}\right]
\end{aligned}
$$

[3] Departemen Agama RI. Al-Qur'an dan terjemahannya. Diponegoro: CV Penerbit Diponegoro, 2005.

Hadley, G. Linear Algebra. Jakarta: Erlangga, 1983

Irwan, Pengantar Aljabar Elementer. Makassar: Alauddin University Press, 2011

Kusumawati, Ririen. Aljabar Linear \& Matriks. Malang: UIN Malang Press, 2009.

7] Pendidikan Matematika UNWIDHA Klaten. Matriks uniter dan matriks Hermite.

http://journal.unwidha.ac.id/index.php/m agistra/article/viewFile/273/222.(28Agu stus 2016)

[8] Pudjiastuti.Matriks: Teori dan Aplikasi. Yogyakarta: Graha Ilmu, 2006.

[9] Purwanto, Heri, dkk. Aljabar Linier. Jakarta: PT. Ercontara Rajawali, 2005.

[10] Saefudin, Abdul Aziz. Aljabar Matriks. Yogyakarta: Graha Ilmu, 2012.

[11] Santosa, Gunawan. Aljabar Linear Dasar. Yogyakarta: ANDI. 2009.

[12] Sibarani, Maslen. Aljabar Linear Dasar. Jakarta: RajaGrafindo Persada, 2013

Diagonalisasi secara simultan pada dua matriks Hermite didapatkan dengan menggunakan persamaan $D_{1}=P^{*} A P$ dan $D_{2}=P^{*} A P$ dimana $D$ adalah matriks diagonal. Sehingga jika diberikan matriks $A$ dan matriks $B$ dengan menggunakan $P^{*}$ dan $P$ yang sama maka diagonalisasi yang diperoleh adalah sebagai berikut :

Ordo $2 \times 2$

$$
\begin{aligned}
& D_{1}=P^{*} A P=\left[\begin{array}{cc}
2+\sqrt{2} & 0 \\
0 & 2-\sqrt{2}
\end{array}\right] \\
& D_{2}=P^{*} B P=\left[\begin{array}{cc}
1+\sqrt{2} & 0 \\
0 & 1-\sqrt{2}
\end{array}\right]
\end{aligned}
$$

[13] Shihab, Quraish. Tafsir Al-Mishbah. Jakarta: Lentera Hati, 2002. 